\title{
Towards new horizons in brain PET
}

\section{Marco Pagani}

Published online: 3 May 2011

(C) Springer-Verlag 2011

There is an increasing need in routine clinical neuroimaging for simple and accessible methodologies which can reduce examination times but still provide reliable information about the status of the disease. More widespread use of PET technology would be favoured by avoiding the investment and running expenses associated with an onsite cyclotron. The clinical implementation of PET would benefit from cost reductions. The use of isotope generators could potentially allow centres remote from a cyclotron to have access to a wide range of radiopharmaceuticals.

The zinc-62/copper-62 $\left({ }^{62} \mathrm{Zn} /{ }^{62} \mathrm{Cu}\right)$ generator is a closeto-optimal radionuclide source for labelling chemically diverse ligands. ${ }^{62} \mathrm{Zn}$ is produced by the nuclear reaction ${ }^{63} \mathrm{Cu}(\mathrm{p}, \mathrm{n}){ }^{62} \mathrm{Zn}$ with a proton beam of $27.5 \mathrm{MeV}$, fitting well with on-demand production by a regional medium-energy cyclotron [1-3]. The generator is compact, is easy to produce and ship and is relatively inexpensive, and the eluate is either automatically chelated by thiosemicarbazone complexes (i.e. ATSM and PTSM) [4] or mixed manually [5]. The 9.3-h half-life of ${ }^{62} \mathrm{Zn}$ limits the use of the generator to a single day, during which up to 20 doses can be produced. Conversely, the 9.7 -min half-life of ${ }^{62} \mathrm{Cu}$ is short enough to offer the opportunity in a single patient to perform sequential studies as well as studies involving dual tracer combinations in which a ${ }^{62} \mathrm{Cu}$ investigation can be

\footnotetext{
M. Pagani $(\bowtie)$

Institute of Cognitive Sciences and Technologies, CNR,

Via Palestro 32,

00185 Rome, Italy

e-mail: marco.pagani@istc.cnr.it

M. Pagani

Department of Nuclear Medicine, Karolinska Hospital,

Stockholm, Sweden

combined with, for example, an ${ }^{18} \mathrm{~F}$ labelled radiopharmaceutical to provide complementary information $[5,6]$.

The almost exclusive $\beta^{+}$emission (97\%) of ${ }^{62} \mathrm{Cu}$ impacts positively on the true coincidences and hence on the sensitivity and count rate, giving good counting statistics even for less-sensitive PET cameras. The short physical halflife of ${ }^{62} \mathrm{Cu}$ and the biodistribution patterns of its thiosemicarbazone complexes result in effective doses $(0.36 \mathrm{mSv} /$ $100 \mathrm{MBq})$ of the same order as ${ }^{15} \mathrm{O}$-water $(0.1 \mathrm{mSv} /$ $100 \mathrm{MBq}$ ), which is in the lower range of the most used radiopharmaceuticals (i.e. ${ }^{18} \mathrm{~F}-\mathrm{FDG}, 1.9 \mathrm{mSv} / 100 \mathrm{MBq}$ ) [7]. On the other hand, the high positron energy of ${ }^{62} \mathrm{Cu}(E$ $\beta^{+}{ }_{\max }=2.93 \mathrm{MeV}$ ) results in a large positron range prior to annihilation and consequently to a significant resolution loss (an intrinsic spatial resolution loss of $4.0 \mathrm{~mm}$ compared to $0.7 \mathrm{~mm}$ for ${ }^{18} \mathrm{~F}$ ). This estimated blur could limit the ability of ${ }^{62} \mathrm{Cu}$ to precisely detect changes in small areas.

In this issue of the European Journal of Nuclear Medicine and Molecular Imaging Isozaki et al. [8] report a wellconducted study with highly accurate assessments of haemodynamic status using a minimally invasive and time-effective methodology. They used for the first time in cerebrovascular disease ${ }^{62} \mathrm{Cu}$-ATSM, a radiopharmaceutical originally developed for probing hypoxic tissue [9] and recently proven to be effective in imaging tumours [5] and acute stroke [6]. They were able to demonstrate a highly significant relationship between the early phase (first 3 min after injection) uptake of ${ }^{62} \mathrm{Cu}$-ATSM and cerebral blood flow images as evaluated by a bolus injection of ${ }^{15} \mathrm{O}$-water. Moreover, the ratio between its late phase (last $10 \mathrm{~min}$ after injection) and the early phase was significantly correlated with the oxygen extraction fraction as measured by a bolus inhalation of ${ }^{15} \mathrm{O}_{2}$. The conclusion was that dynamic PET acquisition with ${ }^{62} \mathrm{Cu}-$ ATSM provides information about the haemodynamic status of patients with chronic cerebrovascular disease equivalent to 
that obtained by ${ }^{15} \mathrm{O}$-labelled tracers. This innovative investigation addresses the very important issue of making functional neuroimaging evaluations less invasive and more easily performed, while maintaining a high level of reliability. In a clinical setting a complete evaluation of brain haemodynamic status by ${ }^{15} \mathrm{O}$ gas tracers including the inhalation of $\mathrm{C}^{15} \mathrm{O}$ and ${ }^{15} \mathrm{O}_{2}$, and the injection of ${ }^{15} \mathrm{O}$-water takes about an hour [10]. Furthermore, the need for repeated manual arterial sampling requires arterial lines and the mandatory presence of an operator beside the bed resulting in a high stress level for the patient. The proposed non-invasive imaging method by a single intravenous injection of ${ }^{62} \mathrm{Cu}$-ATSM provided, in a 20 min examination time, information about both regional cerebral blood flow and hypoxic changes due to ischaemia. This information is extremely relevant in the evaluation of cerebrovascular disease, helping to identify the tissue suffering from chronic misery perfusion which can possibly be saved by neurosurgical treatment.

$\mathrm{Cu}$-ATSM has shown a selective hypoxia-related retention [9, 11-17]. It is highly lipophilic and shows quick penetration through the blood-brain barrier as well as through cell and mitochondrial membranes [18, 19]. Under hypoxic conditions impairment of the electron transport system of mitochondria favours the reduction of $\mathrm{Cu}$-ATSM at the complex I site using NADH as an electron donor [9]. $\mathrm{Cu}(\mathrm{II})-\mathrm{ATSM}$ reduction probably occurs in all cells and results in an unstable $\mathrm{Cu}(\mathrm{I})-\mathrm{ATSM}$, which in turn, in the presence of oxygen, can be oxidized back to $\mathrm{Cu}$ (II)-ATSM and freely diffuse in and out of the cell [20, 21]. In a hypoxic cellular environment $\mathrm{Cu}(\mathrm{I})$-ATSM will slowly and irreversibly dissociate, becoming trapped in the cell and absorbed by the intracellular $\mathrm{Cu}$ pool [9]. The key factors accounting for $\mathrm{Cu}$-ATSM accumulation are probably the high NADH-NADPH concentration and a decrease in intracellular $\mathrm{pH}$ from the over-reduced hypoxic tissue [16]. However, the reductive retention of $\mathrm{Cu}$-ATSM requires intact mitochondria and its accumulation is associated with cell viability (for review see reference [22]).

These biochemical characteristics of Cu-ATSM agents have been previously exploited in studies of tumours in which the definition of the hypoxic regions surrounding the necrotic core is of the utmost importance in the planning of radio- and chemotherapy (for review see reference [14]). Studies have shown that $\mathrm{Cu}$-ATSM distributes mainly in the outer still-viable rim of tumour masses while ${ }^{18} \mathrm{~F}-\mathrm{FDG}$ accumulates in the inner prenecrotic regions [5, 23, 24]. $\mathrm{Cu}$-ATSM agents have also been compared to other hypoxic agents such as 2-nitroimidazoles ( ${ }^{18} \mathrm{~F}$-FMISO) with concordant findings in early and late images (16$20 \mathrm{~h}$ after injection using ${ }^{64} \mathrm{Cu}$ ) [25].

The particular clinical usefulness of ${ }^{62} \mathrm{Cu}$-ATSM in brain investigations lies in the valuable dual information potentially obtained from one single radiopharmaceutical injection. Due to the lipophilicity and quick penetration of ${ }^{62} \mathrm{Cu}$-ATSM through cell membranes, images obtained by summing the dynamic PET data during first $3 \mathrm{~min}$, as in the study by Isozaki et al. [8], will be proportional to blood flow. The latephase images, from the last $10 \mathrm{~min}$ of the ${ }^{62} \mathrm{Cu}$-ATSM data acquisition, will represent the actual redox state of the tissue where high ${ }^{62} \mathrm{Cu}$-ATSM accumulation reveals critical mitochondrial impairment with an increased chance of future irreversible damage; normal uptake will reveal normal viable tissue, and no accumulation will reveal necrotic tissue. This valuable information, along with a minimal examination time of $20 \mathrm{~min}$ and the possibility to plan in advance and examine several patients in the same day might open up a new horizon for clinical applications of PET in brain studies.

In addition to cerebrovascular disease [8] and MELAS [6], ${ }^{62} \mathrm{Cu}$-ATSM could be of use in targeting viable hypoxic tissue with high specificity for planning radiotherapy of brain tumours, in psychiatric studies in which mitochondrial damage is suspected to be a contributing factor, and in neuropsychiatry to elucidate the role of hypoxia in Alzheimer's and Parkinson's diseases. All of these potential advantages of ${ }^{62} \mathrm{Cu}$-ATSM should be carefully taken into account by members of the European community of nuclear medicine for considering the possibility of also producing ${ }^{62} \mathrm{Zn} /{ }^{62} \mathrm{Cu}$ generators on our continent which at the moment are only available in Japan and the USA. The availability of ${ }^{62} \mathrm{Zn} /{ }^{62} \mathrm{Cu}$ generators would possibly increase the number of cerebrovascular and tumour hypoxia studies with a positive impact on both diagnosis and patient treatment.

\section{References}

1. Yagi $\mathrm{M}, \mathrm{Kondo} \mathrm{KA} .62 \mathrm{Cu}$ generator. Int $\mathrm{J}$ Appl Radiat Isot. 1979;30:569-70.

2. Robinson GD, Zielinski FW, Lee AW. The zinc-62/copper-62 generator: a convenient source of copper-62 for radiopharmaceuticals. Int J Appl Radiat Isot. 1980;31:111-16.

3. Fujibayashi Y, Matsumoto K, Yonekura Y, Konishi J, Yokoyama A. A new zinc-62/copper-62 generator as a copper-62 source for PET radiopharmaceuticals. J Nucl Med. 1989;30:1838-42.

4. Haynes NG, Lacy JL, Nayak N, Martin CS, Dai D, Mathias CJ, et al. Performance of a $62 \mathrm{Zn} / 62 \mathrm{Cu}$ generator in clinical trials of PET perfusion agent 62Cu-PTSM. J Nucl Med. 2000;41:309-14.

5. Lohith TG, Kudo T, Demura Y, Umeda Y, Kiyono Y, Fujibayashi $\mathrm{Y}$, et al. Pathophysiologic correlation between $62 \mathrm{Cu}-\mathrm{ATSM}$ and 18F-FDG in lung cancer. J Nucl Med. 2009;50:1948-53.

6. Ikawa $M$, Okazawa $H$, Arakawa $K$, Kudo $T$, Kimura $H$, Fujibayashi $\mathrm{Y}$, et al. PET imaging of redox and energy states in stroke-like episodes of MELAS. Mitochondrion. 2009;9:144-8.

7. Wallhaus TR, Lacy J, Whang J, Green MA, Nickles RJ, Stone CK. Human biodistribution and dosimetry of the PET perfusion agent copper-62-PTSM. J Nucl Med. 1998;39:1958-64.

8. Isozaki M, Kiyono Y, Arai Y, Kudo T, Mori T, Maruyama R, et al. Feasibility of $62 \mathrm{Cu}$-ATSM PET for evaluation of brain ischaemia and misery perfusion in patients with cerebrovascular disease. Eur J Nucl Med Mol Imaging. 2011. doi:10.1007/00259-011-1734-Z. 
9. Fujibayashi Y, Taniuchi H, Yonekura Y, Ohtani H, Konishi J, Yokoyama A. Copper-62-ATSM: a new hypoxia imaging agent with high membrane permeability and low redox potential. J Nucl Med. 1997;38:1155-60.

10. Okazawa H, Kudo T. Clinical impact of hemodynamic parameter measurement for cerebrovascular disease using positron emission tomography and 15O-labeled tracers. Ann Nucl Med. 2009;23:21727.

11. Lewis JS, McCarthy DW, McCarthy TJ, Fujibayashi Y, Welch MJ. Evaluation of 64Cu-ATSM in vitro and in vivo in a hypoxic tumor model. J Nucl Med. 1999;40:177-83.

12. Lewis JS, Sharp TL, Laforest R, Fujibayashi Y, Welch MJ. Tumor uptake of copper-diacetyl-bis(N(4)-methylthiosemicarbazone): effect of changes in tissue oxygenation. J Nucl Med. 2001;42:655-61.

13. Burgman P, O'Donoghue JA, Lewis JS, Welch MJ, Humm JL, Ling CC. Cell line-dependent differences in uptake and retention of the hypoxia-selective nuclear imaging agent $\mathrm{Cu}$-ATSM. Nucl Med Biol. 2005;32:623-30.

14. Krohn KA, Link JM, Mason RP. Molecular imaging of hypoxia. J Nucl Med. 2008;49:129S-48S.

15. Wong TZ, Lacy JL, Petry NA, Hawk TC, Sporn TA, Dewhirst $\mathrm{MW}$, et al. PET of hypoxia and perfusion with $62 \mathrm{Cu}$-ATSM and $62 \mathrm{Cu}-\mathrm{PTSM}$ using a $62 \mathrm{Zn} / 62 \mathrm{Cu}$ generator. AJR Am J Roentgenol. 2008;190:427-32.

16. Holland JP, Lewis JS, Dehdashti F. Assessing tumor hypoxia by positron emission tomography with $\mathrm{Cu}-\mathrm{ATSM}$. Q J Nucl Med Mol Imaging. 2009;53:193-200.

17. Mees G, Dierckx R, Vangestel C, Van de Wiele C. Molecular imaging of hypoxia with radiolabelled agents. Eur J Nucl Med Mol Imaging. 2009;36:1674-86.

18. Fujibayashi Y, Wada K, Taniuchi H, Yonekura Y, Konishi J, Yokoyama A. Mitochondria-selective reduction of $62 \mathrm{Cu}-$ pyruvaldehyde bis(N4-methylthiosemicarbazone) (62Cu-PTSM) in the murine brain; a novel radiopharmaceutical for brain positron emission tomography (PET) imaging. Biol Pharm Bull. 1993;16:146-9.

19. Taniuchi H, Fujibayashi Y, Okazawa H, Yonekura Y, Konishi J, Yokoyama A. Cu-pyruvaldehyde-bis(N4-methylthiosemicarbazone) (Cu-PTSM), a metal complex with selective NADHdependent reduction by complex I in brain mitochondria: a potential radiopharmaceutical for mitochondria-functional imaging with positron emission tomography (PET). Biol Pharm Bull. 1995;18:1126-9.

20. Dearling JL, Lewis JS, Mullen GE, Welch MJ, Blower PJ. Copper bis(thiosemicarbazone) complexes as hypoxia imaging agents: structure-activity relationships. J Biol Inorg Chem. 2002;7:24959.

21. Maurer RI, Blower PJ, Dilworth JR, Reynolds CA, Zheng Y, Mullen GE. Studies on the mechanism of hypoxic selectivity in copper bis(thiosemicarbazone) radiopharmaceuticals. J Med Chem. 2002;45:1420-31.

22. Dearling JL, Packard AB. Some thoughts on the mechanism of cellular trapping of $\mathrm{Cu}(\mathrm{II})-\mathrm{ATSM}$. Nucl Med Biol. 2010;37:23743.

23. Obata A, Yoshimoto M, Kasamatsu S, Naiki H, Takamatsu S, Kashikura K, et al. Intra-tumoral distribution of (64)Cu-ATSM: a comparison study with FDG. Nucl Med Biol. 2003;30:529-34.

24. Yoshii Y, Furukawa T, Kiyono Y, Watanabe R, Waki A, Mori T, et al. Copper-64-diacetyl-bis (N4-methylthiosemicarbazone) accumulates in rich regions of CD133 + highly tumorigenic cells in mouse colon carcinoma. Nucl Med Biol. 2010;37:395-404.

25. Dence CS, Ponde DE, Welch MJ, Lewis JS. Autoradiographic and small-animal PET comparisons between (18)F-FMISO, (18)FFDG, (18)F-FLT and the hypoxic selective (64)Cu-ATSM in a rodent model of cancer. Nucl Med Biol. 2008;35:713-20. 